\title{
Transmission Holographic Gratings Using Siloxane-containing Liquid Crystalline Compounds. Importance of Chemical Structure of Polymer Matrix Components
}

\author{
Man He, Yeong Hee CHO, and Yusuke KawaKAMI ${ }^{\dagger}$ \\ School of Materials Science, Japan Advanced Institute of Science and Technology (JAIST), \\ Asahidai 1-1, Nomi 923-1292, Japan
}

(Received January 4, 2006; Accepted March 1, 2006; Published June 9, 2006)

\begin{abstract}
Siloxane-containing liquid crystalline compounds were found effective to induce distinct phase separation, when combined with multi-functional acrylates, over a wide concentration range from $6 \mathrm{wt} \%$ to $20 \mathrm{wt} \%$ in the formation of holographic gratings. Use of ring-opening polymerizable bi-functional epoxides as one of the reactive cross-linking matrix component together with penta- or tetra acrylate initiated by 3,3'-carbonylbis(7-diethylaminocoumarin)-diphenyliodonium hexafluorophosphate greatly improved the diffraction efficiency and angular selectivity of the formed grating. Fine gratings with $70 \%$ and $78 \%$ diffraction efficiency and angular selectivity of about $5^{\circ}$ were formed with 10 wt \% 4-cyano-4'-\{(5-heptamethyltrisiloxan-1-yl)pentyloxy $\}$ biphenyl and 4-cyanophenyl 4-\{(5-heptamethyltrisiloxan-1-yl)pentyloxy\}benzoate using pentaerythrytol pentaacrylate-neopentylglycol diglycidyl ether-tripropylene glycol diacrylate (4:5:1) as the polymer matrix component. [doi:10.1295/polymj.PJ2005201]

KEY WORDS Siloxane-containing Liquid Crystalline Compound / Multi-functional Acrylate / Bi-functional Epoxide / Photo-polymerization / Phase Separation / Holographic Grating /
\end{abstract}

Since holographic storage enables fast data transfer rates by simultaneous writing and reading, an upsurge of interest in optical holography has been noticed in the past decade. Photopolymers and polymer dispersed liquid crystals have been mainly investigated for holographic storage systems. Kawabata reported the holographic recording based on photopolymer system. ${ }^{1}$ R. L. Sutherland ${ }^{2-7}$ proposed a grating formation via the phase separation of liquid crystal (LC) during the photo-polymerization irradiated by two coherent interfering laser beams. Grating was formed as a refractive index-modulated interference fringe pattern of stratified alternating layers of LC and polymer (holographic polymer dispersed liquid crystal, HPDLC). Principle and application of PDLC systems have been extensively studied. ${ }^{8-13}$ An important role of LC is the response against electric field in the formed gratings, which makes it possible to be applied as display devices, ${ }^{14-16}$ switchable lenses, ${ }^{17,18}$ and wave-guided switches. ${ }^{19}$ In these systems, control of the morphology of the LC droplets in a photo-polymerized matrix, which depends on the LC content, the cure rate, and compatibility among the components, is the key to develop high performance holographic films with controllable and repeatable electro-optic performances.

For HPDLC systems, the principal role of LC is to phase-separate by the diffusion during the polymerization of multi-functional monomer giving polymer matrix, and to give high modulation of the refractive index of the formed gratings. The phase separation is a balance between the rate of diffusion of LC and the rate of gelation of the polymer network dictated by the polymerization kinetics. In designing efficient holographic gratings, much attention has been focused mainly on the elucidation of the effects of functionality of photo-polymerizable monomers. ${ }^{20-23}$ Little attention has been paid to the importance of the chemical structure. In our previous study, it was found that siloxane-containing epoxide monomers were effective for inducing effective phase separation. ${ }^{24,25}$ It was also reported that introduction of fluorinated alky group to acrylate diluent enhance the phase separation. ${ }^{26}$

One of the objectives of this paper is to show the effectiveness of siloxane-containing spacer of liquid crystalline compound to induce distinct phase separation over that with long alkyl spacers in fabrication of transmission gratings formation. The second objective is to show the importance of bi-functional epoxide as a cross-linking polymer matrix component to enhance the diffraction efficiency. In these systems, the type of the initiating system also played an important role. Real-time diffraction efficiency and angular selectivity of the final grating were evaluated, and the wellconstructed morphology of the formed gratings was evidenced by scanning electro microscope (SEM) observation.

${ }^{\dagger}$ To whom correspondence should be addressed (Tel: +81-761-51-1630, Fax: +81-761-51-1635, E-mail: kawakami@jaist.ac.jp). 


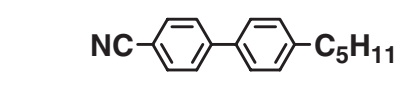

4-cyano-4'-pentylbiphenyl $5 \mathrm{CB}$

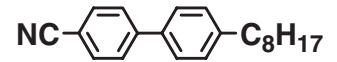

4-cyano-4'-octylbiphenyl $8 \mathrm{CB}$

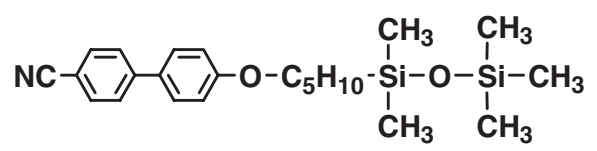

4-cyano-4'-\{(5-pentamethyldisiloxanyl)pentyloxy $\}$ biphenyl 9OS2CB

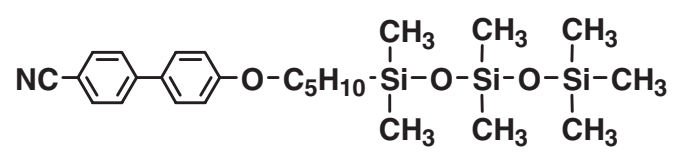

4-cyano-4'-\{(5-heptamethyltrisiloxan-1-yl)pentyloxy $\}$ biphenyl $110 S 3 \mathrm{CB}$

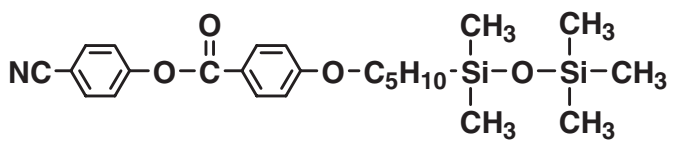

4-cyanophenyl 4-\{5-(pentamethyldisiloxanyl)pentyloxy\}benzoate 9OS2BE

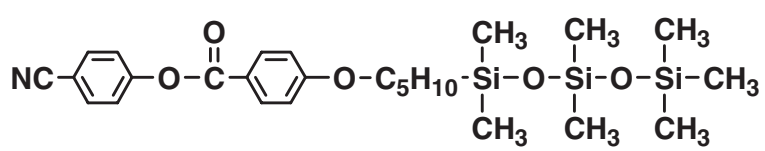

4-cyanophenyl 4-\{5-(pentamethyltrisiloxan-1-yl)pentyloxy\}benzoate 11OS3BE

Figure 1. Structures and abbreviations of liquid crystalline compounds.

\section{EXPERIMENTAL}

\section{Materials Used in Holographic Grating Formation}

Unless stated otherwise, all reagents and solvents were of commercial grade and used as received without further purification. Chemical structures of the liquid crystalline compounds used in this study are shown in Figure 1.

4-Cyano-4'-pentylbiphenyl and 4-cyano-4'-octylbiphenyl were purchased from Aldrich Chemical. 4Pentenyl group was introduced by substitution reaction in the synthesis of 4-cyanophenyl-4'-pentenyloxybiphenyl. The crude products were purified by recrystallization from ethanol $\sim 70 \%$ yield. The siloxane chains were introduced via hydrosilylation of the olefinic group by terminal silane-functionalized oligodimethylsiloxanes. The crude products were firstly passed through a silica gel column with hexane, and further purified by HPLC using hexane:ethy acetate = $20: 1$ as a mobile phase to obtain pure compound in $\sim 90 \%$ yield.

${ }^{1} \mathrm{H}$ NMR $\left(\delta, \mathrm{CDCl}_{3}, 500 \mathrm{MHz}\right)$.

9OS2CB: $0.05\left[\mathrm{~s}, 6 \mathrm{H}, \mathrm{OSi}\left(\mathrm{CH}_{3}\right)_{2}\right], 0.07[\mathrm{~s}, 9 \mathrm{H}$, $\left.\mathrm{OSi}\left(\mathrm{CH}_{3}\right)_{3}\right], 0.55$ [t, $J=8.1 \mathrm{~Hz}, 2 \mathrm{H}, \mathrm{CH} 2 \mathrm{Si}\left(\mathrm{CH}_{3}\right)_{2}$, 1.42-1.47 [m, 2H, $\left.\mathrm{CH}_{2} \mathrm{CH}_{2} \mathrm{Si}\right], 1.48-1.54[\mathrm{~m}, 2 \mathrm{H}$, $\mathrm{CH}_{2} \mathrm{CH}_{2} \mathrm{CH}_{2} \mathrm{Si}$ ], 1.82-1.87 [m, 2H, OCH $\mathrm{CH}_{2}$ ], 4.04 [t, $J=6.5 \mathrm{~Hz}, 2 \mathrm{H}, \mathrm{OCH}_{2}$ ] $7.00[\mathrm{~d}, J=8.8 \mathrm{~Hz}, 4 \mathrm{H}$,

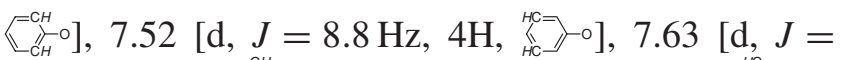

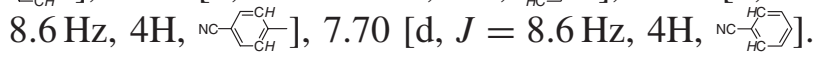

11OS3CB: 0.08 [s, 6H, OSi $\left.\left(\mathrm{CH}_{3}\right)_{2} \mathrm{O}\right], 0.13[\mathrm{~s}, 6 \mathrm{H}$, $\mathrm{CH}_{2} \mathrm{Si}\left(\mathrm{CH}_{3}\right)_{2}$ ] 0.15 [s, 9H, OSi $\left.\left(\mathrm{CH}_{3}\right)_{3}\right), 0.63$ [t, $J=$ $\left.7.8 \mathrm{~Hz}, 2 \mathrm{H}, \mathrm{CH}_{2} \mathrm{Si}\left(\mathrm{CH}_{3}\right)_{2}\right], 1.45-1.50\left[\mathrm{~m}, 2 \mathrm{H}, \mathrm{CH}_{2^{-}}\right.$ $\left.\mathrm{CH}_{2} \mathrm{Si}\left(\mathrm{CH}_{3}\right)_{2}\right], 1.51-1.55\left[\mathrm{~m}, 2 \mathrm{H}, \mathrm{CH}_{2} \mathrm{CH}_{2} \mathrm{CH}_{2} \mathrm{Si}-\right.$ $\left.\left(\mathrm{CH}_{3}\right)_{2}\right], 1.80-1.86\left[\mathrm{~m}, 2 \mathrm{H}, \mathrm{OCH}_{2} \mathrm{CH}_{2}\right], 3.98[\mathrm{t}, J=$

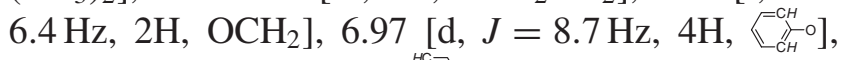
$7.47\left[\mathrm{~d}, J=8.7 \mathrm{~Hz}, 4 \mathrm{H},{ }_{\mathrm{Hc}}^{\mathrm{Hc}} \mathrm{c}-\mathrm{d}-\mathrm{o}\right], 7.56[\mathrm{~d}, J=8.2 \mathrm{~Hz}$,

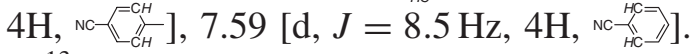

${ }^{13}$ C NMR: 0.027, 1.080, 1.622, 18.01, 22.88, 28.79, $29.49,67.85,109.87,114.88,118.64,126.68,127.99$, 130.83, 132.19, 144.87, 159.66.

9OS2BE: $0.05\left[\mathrm{~s}, 6 \mathrm{H}, \mathrm{OSi}\left(\mathrm{CH}_{3}\right)_{2}\right], 0.06[\mathrm{~s}, 9 \mathrm{H}$, $\left.\mathrm{OSi}\left(\mathrm{CH}_{3}\right)_{3}\right], 0.57$ [t, $J=7.9 \mathrm{~Hz}, 2 \mathrm{H}, \mathrm{CH}_{2} \mathrm{Si}\left(\mathrm{CH}_{3}\right)_{2}$, $1.40-1.43\left[\mathrm{~m}, 2 \mathrm{H}, \mathrm{CH}_{2} \mathrm{CH}_{2} \mathrm{Si}\right], 1.45-1.48[\mathrm{~m}, 2 \mathrm{H}$, $\left.\mathrm{CH}_{2} \mathrm{CH}_{2} \mathrm{CH}_{2} \mathrm{Si}\right], \quad 1.82-1.87$ [m, 2H, $\mathrm{OCH}_{2} \mathrm{CH}_{2}$, $4.06\left[\mathrm{t}, J=6.6 \mathrm{~Hz}, 2 \mathrm{H}, \mathrm{OCH}_{2}\right], 6.98[\mathrm{~d}, J=8.8 \mathrm{~Hz}$,

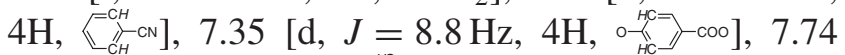
$[\mathrm{d}, J=8.8 \mathrm{~Hz}, 4 \mathrm{H}$,

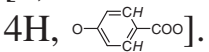

11OS3BE: 0.03 [s, 6H, OSi $\left(\mathrm{CH}_{3}\right)_{2} \mathrm{O}$ ], 0.08 [s, 6H, $\left.\mathrm{CH}_{2} \mathrm{Si}\left(\mathrm{CH}_{3}\right)_{2}\right], 0.09$ [s, 9H, OSi $\left.\left(\mathrm{CH}_{3}\right)_{3}\right], 0.58$ [t, $J=$ $\left.7.8 \mathrm{~Hz}, 2 \mathrm{H}, \mathrm{CH}_{2} \mathrm{Si}\left(\mathrm{CH}_{3}\right)_{2}\right], 1.41-1.43\left[\mathrm{~m}, 2 \mathrm{H}, \mathrm{CH}_{2}-\right.$ $\left.\mathrm{CH}_{2} \mathrm{Si}\left(\mathrm{CH}_{3}\right)_{2}\right], 1.46-1.49$ [m, $2 \mathrm{H}, \mathrm{CH}_{2} \mathrm{CH}_{2} \mathrm{CH}_{2} \mathrm{Si}-$ $\left.\left(\mathrm{CH}_{3}\right)_{2}\right], 1.85-1.90\left[\mathrm{~m}, 2 \mathrm{H}, \mathrm{OCH}_{2} \mathrm{CH}_{2}\right], 4.05[\mathrm{t}, J=$ $\left.6.4 \mathrm{~Hz}, 2 \mathrm{H}, \mathrm{OCH}_{2}\right], 6.96\left[\mathrm{~d}, J=8.8 \mathrm{~Hz}, 4 \mathrm{H}, \mathbb{E}_{\substack{\mathrm{C} H \\ \mathrm{CH}}}^{\mathrm{C}}\right]$,

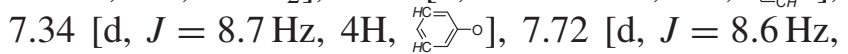




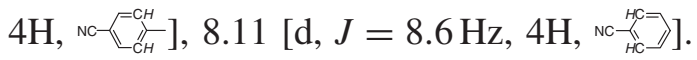

Phase transition temperatures of the compounds were evaluated by differential scanning calorimeter (DSC) with a cooling rate of $5^{\circ} \mathrm{C} / \mathrm{min}$. All the transitions were enantiotropic, and the results were tabulated in Table I.

Multi-functional compounds used as matrix compo-

Table I. Phase transition temperatures of liquid crystalline compounds

\begin{tabular}{lrcr}
\hline \multirow{2}{*}{ Liquid crystal } & \multicolumn{3}{c}{ Phase transition temperatures } \\
& $\mathrm{T}_{\mathrm{S}-\mathrm{C}}$ & $\mathrm{T}_{\mathrm{N}-\mathrm{S}}$ & $\mathrm{T}_{\mathrm{I}-\mathrm{N}}$ \\
\hline $\mathbf{5 C B}$ & 24 & - & 35 \\
$\mathbf{8 C B}$ & 22 & 34 & 41 \\
11OCB & 56 & 73 & 76 \\
9OS2CB & 30 & - & 50 \\
11OS3CB & -10 & - & 29 \\
9OS2BE & nd & -14 & $\sim-10$ \\
11OS3BE & -47 & 1.9 & 36 \\
\hline
\end{tabular}

In second cooling. nents are shown in Figure 2.

$N$-vinylpyrrolidone (NVP) and benzyl glycidyl ether (BGE) were used as mono-functional reactive diluents. Abbreviations $\mathbf{F}$ and $\mathbf{R}$ were used to indicate acrylate $(\mathbf{F})$ and epoxide $(\mathbf{R})$ monomer and the numerals indicate the functionality, for example, $\mathbf{5 F}$ and $\mathbf{2 R}$ indicate penta-functional acrylate and bi-functional epoxide, respectively. $\mathbf{S 2}$ and $\mathbf{S 3}$ indicate disiloxane and trisiloxane.

NVP, BGE, tripropylene glycol diacrylate (2F), trimethylolpropane triacrylate $(\mathbf{3 F})$, pentaerythritol tetraacrylate (4F), dipentaerythritol pentaacrylate $(\mathbf{5 F})$, and ring-opening polymerizable di-functional epoxides were obtained from Aldrich Chemical. The photo-sensitizer, Rose Bengal (RB) and the initiator N-phenylglycine (NPG) were obtained from Kanto Chemical. 3,3'-Carbonylbis(7-diethylaminocoumarin) (KC)-diphenyliodonium hexafluorophosphate (DPI) initiator system as shown in Figure 3, which produces proton and radical species, were also used.

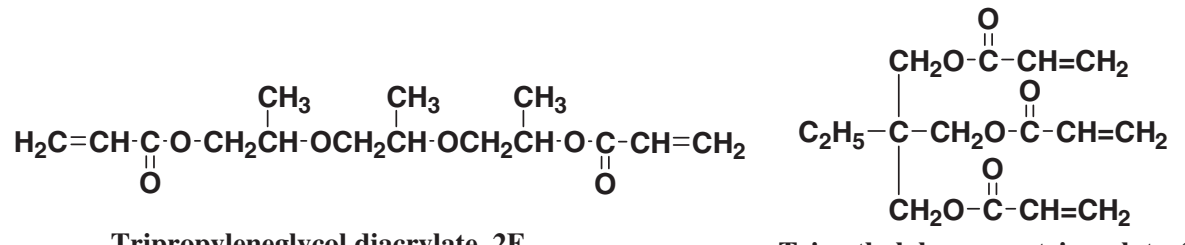

Tripropyleneglycol diacrylate, $2 \mathrm{~F}$<smiles>C=CC(=O)OCC(COC(=O)C=C)(COC(=O)C=C)COC(=O)C=C</smiles>

Pentaerythritol tetraacrylate, $4 \mathrm{~F}$<smiles>CC(C)(COCC1CO1)COCC1CO1</smiles>

Neopentyl glycol diglycidylether, N2R
Trimethylolpropane triacrylate, $3 \mathrm{~F}$<smiles>C=CC(=O)OCC(CO)(COC(=O)C=C)CC(COC(=O)C=C)(COC(=O)C=C)COC(=O)C=C</smiles>

Dipentaerythritol pentaacrylate, $5 \mathrm{~F}$

Figure 2. Structures and abbreviations of matrix components.

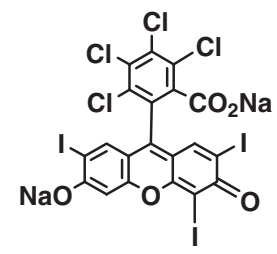

Rose Bengal, RB

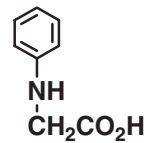

$N$-phenylglycine, NPG

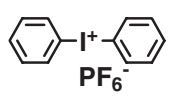

3,3'-carbonylbis(7-diethylaminocoumarin), $\mathbf{K C}$

Diphenyliodonium hexafluorophosphate, DPI

Figure 3. Structures and abbreviations of photo-sensitizers and photo-initiators. 


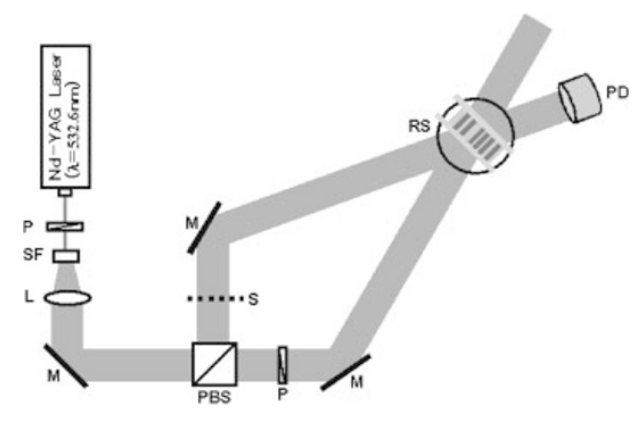

$\mathbf{P}(1 / 2 \lambda$ Plate), SF (Spatial filter), L (Collimating lens), M (Mirror), PBS (Polarizing beam Splitter), RS (Rotational stage), PD (Photo detector)

Figure 4. Experimental setup of holographic recording.

\section{Fabrication of Holographic Grating}

The photo-polymerization solution was prepared under diminished white light to eliminate any unexpected photo-polymerization before holographic recording. The solution for radical recording consisted of a multi-functional acrylate, RB, NPG, NVP and a liquid crystal in varying weight concentration ratio. Typical photo-polymerization solution consisted of matrix $(90 \mathrm{wt} \%)$ [multi-functional acrylate $(40 \mathrm{wt} \%)$ : NVP (60 wt \%)] and a liquid crystal (10 wt \%). Just before irradiation, $0.4 \mathrm{wt} \% \mathbf{R B}$ and $3 \mathrm{wt} \%$ NPG were added, and the mixture was vigorously stirred for about $5 \mathrm{~min}$ to obtain a clear homogeneous solution, and dropped into a cell between the space of two glass slides separated by $20 \mu \mathrm{m}$ to control the thickness of the sample. In the case of the recording using epoxide derivatives, a part of multi-functional acrylate and NVP were substituted by a bi-functional epoxide N2R and BGE, respectively. The initiator DPI-KC system was used.

Holographic transmission gratings were formed by two coherent beams of Nd-YAG laser $(\lambda=532 \mathrm{~nm})$ (Coherent Inc., Verdi-V2) of equal intensity with a true power of $15 \mathrm{~mW} / \mathrm{cm}^{2}$ as illustrated in Figure 4. The beams were collimated and expanded by spatial filters and lens.

\section{Analysis of Diffraction Efficiency and Morphology of Gratings}

The diffraction efficiency (DE) was defined as the relative ratio of diffraction intensity $\left(I_{d}\right)$ to the sum of transmitted beam intensities $\left(I_{d}+I_{t}\right)$ after recording, as illustrated in Figure 5.

The inter beam angle was set to $16^{\circ}$ against a line perpendicular to the plane of the recording cell. Realtime diffraction efficiency was measured by monitoring the intensity of diffracted beam simultaneously when the shutter was closed at a given time during the hologram recording. After recording, all the samples were post-cured under a UV lamp to complete the photo-polymerization of the remaining functional

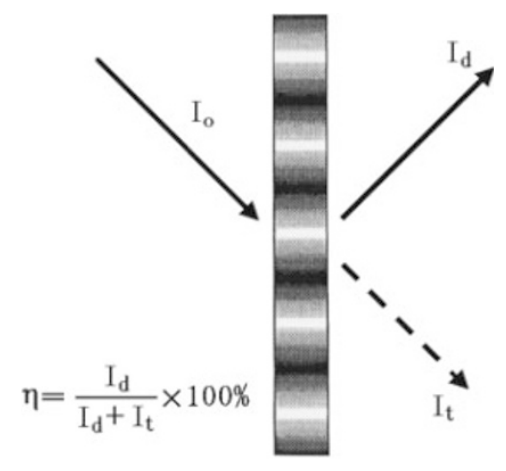

Figure 5. Diffraction efficiency of grating.

groups for about $5 \mathrm{~min}$, and the diffraction efficiency and the angular selectivity were determined by rotating the hologram precisely by constant angle using motor-driven controller with the shutter closed to cut-off the reference light. Holographic gratings were also fabricated by changing the laser intensity and irradiation time, and the optimum condition was established to obtain the highest diffraction efficiency, resolution, and long-term stability after recording.

Samples used for SEM were prepared by freezefracturing the cells using liquid nitrogen and extracting a liquid crystal with ethanol.

\section{RESULTS AND DISCUSSION}

\section{Factors to Determine the Diffraction Efficiency of the} Grating Formation

For a simple transmission grating, Kogelnik's coupled wave theory ${ }^{27}$ gives the maximum diffraction efficiency.

$$
\eta=\sin ^{2}(\pi \Delta \mathrm{nT} / \lambda)
$$

Where $\eta$ is the maximum diffraction efficiency, $\Delta \mathrm{n}$ is the modulation of refractive index, $\mathrm{T}$ is the film thickness, and $\lambda$ is the recording wavelength.

In our experiments, the wavelength was fixed, and rectangular distribution profile of the polymer matrix was assumed in the ideal case. Accordingly, although the diffraction efficiency in the present study does not hold strictly to Kogelnik's equation, this equation is useful to semi-quantitatively evaluate the diffractive efficiency relating to the $\Delta \mathrm{n}$ and $\mathrm{T}$.

The important factors to control the phase separation between polymer matrix and liquid crystal are: 1) distinct phase separation of liquid crystal from polymer matrix, 2) balance between polymerization rate to give cross-linked polymer matrix and diffusion of monomers and liquid crystal. Structure and functionality of multi-functional monomers in polymerizable solution are important to determine the polymerization rate. The diffusibility of monomer and liquid crystal is influenced by the chemical structure. 
Table II. Effect of concentration of functional groups of multi-functional acrylate on grating formation

\begin{tabular}{cllc}
\hline No & \multicolumn{1}{c}{$\begin{array}{c}\text { Matrix } \\
(90 \mathrm{wt} \%)\end{array}$} & $\begin{array}{l}\text { Liquid crystal } \\
(10 \mathrm{wt} \%)\end{array}$ & DE $(\%)$ \\
\hline 1 & $\mathbf{5 F}: \mathbf{N V P}=4: 6$ & $\mathbf{1 1 O S 3 C B}$ & 38 \\
2 & 4F:NVP $=4: 6$ & $\mathbf{1 1 O S 3 C B}$ & 43 \\
3 & 3F:NVP $=4: 6$ & $\mathbf{1 1 O S 3 C B}$ & 24 \\
4 & $\mathbf{5 F}: \mathbf{2 F}: \mathbf{N V P}=4: 5: 1$ & $\mathbf{1 1 O S 3 C B}$ & 1 \\
5 & $\mathbf{5 F}: \mathbf{N V P}=4: 6$ & $\mathbf{5 C B}$ & 3 \\
\hline
\end{tabular}

Polymerization solution included $0.4 \mathrm{wt} \% \mathbf{R B}$ and $3 \mathrm{wt} \%$ NPG.

Superiority of Liquid Crystals with Siloxane Spacer over those with Alkyl Spacer in Grating Formation

In general, the miscibility of liquid crystals with long alkyl or alkoxy spacer with acrylate matrix components was very low at room temperature, and gratings with high diffraction efficiency could not be obtained by simple radical polymerization systems. Liquid crystalline compounds with siloxane spacer, such as 11OS3CB were completely miscible with the photo-polymerization solution. The change in real-time diffraction efficiencies against irradiation time for the solution with $10 \mathrm{wt} \%$ LC compound and various NVP wt \% in [multifunctional acrylate:NVP] (totally $90 \mathrm{wt} \%, \mathbf{5 F}=40 \mathrm{wt} \%$ and $\mathbf{N V P} 60 \mathrm{wt} \%$ gives the relative NVP weight of 54\%) with radical initiator system RB and NPG are shown in Table II.

The systems with $36 \mathrm{wt} \% \mathbf{5 F}$ or $\mathbf{4 F}$ with $10 \mathrm{wt} \%$ $110 S 3 C B$ gave the highest diffraction efficiency of 38 and 43\%, respectively (No 1 and 2). The system with the same concentration of $\mathbf{3 F}$ gave relatively lower diffraction efficiency of $24 \%$ (No 3 ). When a major part of NVP was replaced by a bi-functional $\mathbf{2 F}$, the diffraction efficiency was dramatically decreased (No 4), which suggested the too rapid forma- tion of cross-linking matrix by a fast polymerization of 5F-2F system having too high double bond concentration. Liquid crystalline compounds with short alkyl spacers, typically shown for 4-cyano-4'pentylbiphenyl (5CB), gave low final diffraction efficiency of $3 \%$ (No 5) even with 5F-NVP. Diffraction efficiency rapidly reached $25 \%$ in the initial $20 \mathrm{~s}$ exposure, and decrease gradually to the final diffraction efficiency of $3 \%$, which suggested the incomplete phase separation of $\mathbf{5 C B}$ and other components by the rapid formation of cross-linked matrix by the polymerization of $\mathbf{5 F}$ NVP system, followed by an equilibration by diffusion and relaxation of the $\mathrm{LC}$ and other components. These facts indicate that optimum concentration of the acrylate functional groups exists to obtain high diffraction efficiency. The role of the siloxane component seems not only to contribute to increase the solubility, but also to make the diffusion of the LC easier. We reported the influence of siloxane bonds on the viscosity of the compounds, and indicated the importance of low viscosity of siloxane-containing compound in fabrication of gratings with high diffraction efficiency. ${ }^{28}$

SEM morphology of the grating was shown in Figure 6. In SEM picture of the ethanol-washed sample in Figure 6, it was observed that the siloxane-containing 11OS3CB well phase-separated from the polymer matrix. The width of liquid crystalline layer is close to $10 \%$ of spacing, which corresponds to the feed ratio of 110S3CB. Each layer could be peeled off, which strongly suggested the well phase separated layered structure of the grating. Thus, it was clearly shown in Table II that $10 \mathrm{wt} \%$ of 110S3CB together with 5F:NVP $=4: 6$ as photo-polymerization solution was quite effective to cause an efficient phase separation in grating formation leading to high diffraction efficiency.

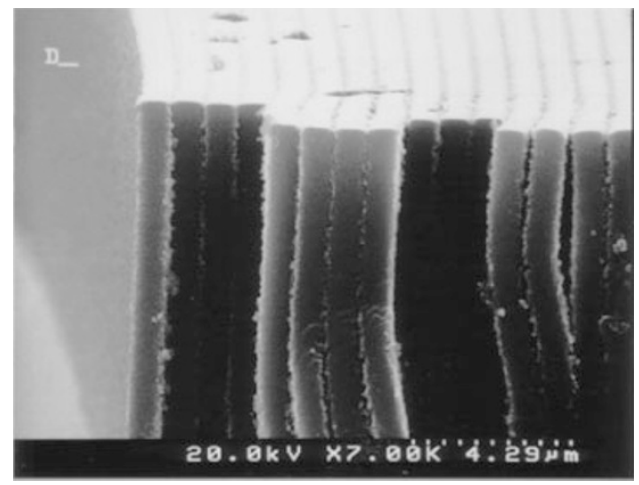

(a)

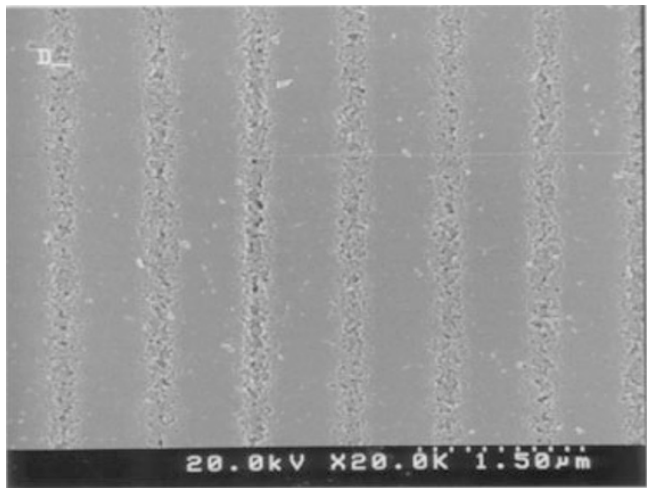

(b)

Figure 6. SEM morphology of grating (DE 38\%) prepared with 11OS3CB (10 wt \%) and $90 \mathrm{wt} \%$ matrix (5F:NVP = 4:6): (a) Side view (b) Top view. 
Table III. Improvement of diffraction efficiency by the co-presence of bis(epoxide) $\mathbf{N} 2 \mathbf{R}$

\begin{tabular}{rlcc}
\hline No & \multicolumn{1}{c}{ Matrix } & $\begin{array}{c}\text { PS/PI } \\
(0.4 \text { wt } \% / 3 \text { wt } \%)\end{array}$ & DE $(\%)$ \\
\hline 6 & 5F:2F:NVP $=4: 5: 1$ & RB/NPG & 2 \\
7 & 5F:2F:NVP $=4: 5: 1$ & KC/DPI & 2 \\
8 & 5F:2F:BGE $=4: 5: 1$ & KC/DPI & 2 \\
9 & 5F:N2R:BGE $=4: 5: 1$ & RB/NPG & 18 \\
10 & 5F:N2R:BGE $=4: 5: 1$ & KC/DPI & 70 \\
\hline
\end{tabular}

Photo-polymerization solution consisted of $90 \mathrm{wt} \%$ matrix (including the initiator) and $10 \mathrm{wt} \% \mathbf{1 1 O S 3 C B}$.

Improvement of Diffraction Efficiency by the Coexistence of Radically and Cationically Polymerizable Matrix Components

The more important findings in this study are the influence of the bi-functional epoxide used together with multi-functional acrylates. The results are shown in Table III.

The diffraction efficiency was not improved when the initiator was simply changed from radical system RB-NPG (No 6) to cationic system KC-DPI (No 7) for the multi-functional acrylate recording solutions. The efficiency was not improved either, by simply changing NVP to BGE, when radical initiator system was used (No 8). Polymerization solution in which NVP was replaced by bi-functional epoxide, N2R, gave increased diffraction efficiency (No 9), and resulted in a dramatic increase in diffraction efficiency when the initiator was changed from RB-NPG to KC-DPI, which could initiate cationic polymerization (No 10). The highest diffraction efficiency in radical system, namely $43 \%$ was improved to $70 \%$ for the system 5F-N2R-BGE [4:5:1]. Such effect was considered to be caused by relatively fast initial cross-linking by $\mathbf{5 F}$ followed by the slower cross-linking of the system by $\mathbf{N 2 R}$. Dilution of functionality of $\mathbf{5 F}$ with $\mathbf{N 2 R}$, might result in the low extent of the initial cross-linking, but the successive cross-linking by $\mathbf{N} 2 \mathbf{R}$ pushed the liquid crystal out more effectively than the case of the rapid cross-linking by $\mathbf{5 F}$ alone. Thus, gradual increase in diffraction efficiency was observed. The reason for the moderate increase in diffraction efficiency for 5F-N2R-BGE system by RBNPG might be a dilution effect of the too high double bond concentration to optimize the cross-linking and diffusion balance (No 9).

The effect of the concentration of functionality of multi-functional acrylate in the presence of $\mathbf{N} 2 \mathbf{R}$ was shown in Table IV.

When the functionality of radically polymerizable monomer was changed from 5 (No 10) to 4 (No 11) or 3 (No 12), the diffraction efficiency was dropped to $30-40 \%$ compared with $70 \%$ for the pentaacrylate $\mathbf{5 F}$ system. Importance of the functionality of the
Table IV. Effect of functionality of multi-functional acryalte on the diffraction efficiency in the system with $\mathbf{N 2 R}$ as bis(epoxide)

\begin{tabular}{cccc}
\hline No & Matrix & Gelation time (s) & DE (\%) \\
\hline 10 & 5F:N2R:BGE $=4: 5: 1$ & 12 & 70 \\
11 & 4F:N2R:BGE $=4: 5: 1$ & 15 & 31 \\
12 & 3F:N2R:BGE $=4: 5: 1$ & 15 & 42 \\
\hline
\end{tabular}

Photo-polymerization solution consisted of $90 \mathrm{wt} \%$ matrix (including KC/DPI) and $10 \mathrm{wt} \% \mathbf{1 1 O S 3 C B}$.

Table V. Effects of concentration of N2R on the diffraction efficiency

\begin{tabular}{ccc}
\hline No. & 5F:N2R:BGE & DE $(\%)$ \\
\hline 13 & $4: 3: 3$ & 26 \\
14 & $4: 4: 2$ & 49 \\
10 & $4: 5: 1$ & 70 \\
15 & $4: 6: 0$ & 60 \\
\hline
\end{tabular}

Polymerization solution consisted of $90 \mathrm{wt} \%$ matrix, including $0.4 \mathrm{wt} \% \mathbf{K C}$ and $3 \mathrm{wt} \%$ DPI and $10 \mathrm{wt} \% \mathbf{1 1 O S 3 C B}$.

acrylate to controll the cross-linking and diffusion of LC was shown, even in these systems. Clearly phaseseparated structure could not be observed by SEM for the sample prepared from 3F:N2R:BGE $=4: 5: 1$. The basic driving force of phase-separation should be the cross-linking by multi-functional acrylates. The effects of the concentration of $\mathbf{N} 2 \mathbf{R}$ on diffraction efficiency were shown in Table V.

Considerably high concentration of $\mathbf{N 2 R}$ was required to obtain high diffraction efficiency (No 10, 15). The efficiency was also dropped by reducing the amount of the initiator. When $1.5 \mathrm{wt} \%$ initiator was used the diffraction efficiency dropped to $24 \%$, in case of 5F:N2R:BGE $=4: 5: 1$.

When bis(epoxide) groups were connected with bis(phenol)A group, the diffraction efficiency was also reduced $(20 \%)$.

Effect of the Concentration of $11 O S 3 C B$ on the Diffraction Efficiency

The effect of the concentration of $110 S 3 C B$ on the grating morphology was shown in Figure 7.

$10 \mathrm{wt} \%$ 110S3CB gave better phase-separated grating than that with $20 \mathrm{wt} \%$. It was found that in this system the optimum concentration of $110 S 3 C B$ was about $10 \mathrm{wt} \%$.

Effects of the structure of the mesogen and the length of the siloxane terminal group in grating formation under the same concentration were shown in Table VI.

There was no significant influence on the diffraction efficiency of the gratings made with these liquid crystals of different chemical structure, which seems to in- 


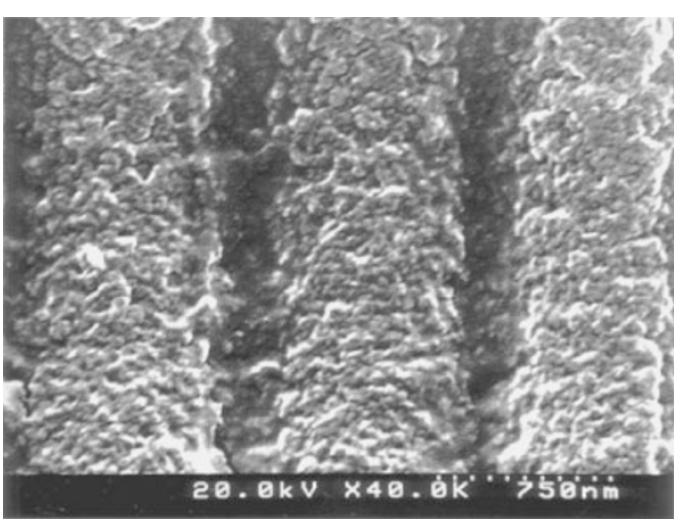

(a)

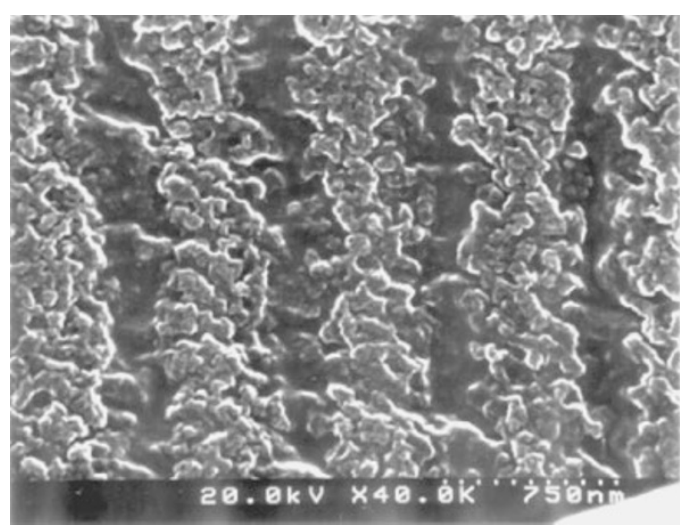

(b)

Figure 7. Effect of concentration of $110 S 3 C B$ on grating morphology. Gratings prepared with $\mathbf{5 F}: \mathbf{2 R}: \mathbf{B G E}=4: 5: 1$ and with (a) $10 \mathrm{wt} \%$ (b) $20 \mathrm{wt} \%$ of $\mathbf{1 1 O S 3 C B}$.

Table VI. Effect of the structure of mesogen and length of siloxane spacer on the diffraction efficiency

\begin{tabular}{ccc}
\hline No. & SLC $(10 \mathrm{wt} \%)$ & DE $(\%)$ \\
\hline 16 & 9OS2CB & 68 \\
10 & 11OS3CB & 70 \\
17 & 9OS2BE & 73 \\
18 & 11OS3BE & 78 \\
\hline
\end{tabular}

dicate that the siloxane terminal group played essentially important role on the grating formation than the mesogenic group. We already pointed out that disiloxane chain is enough to reduce the glass transition temperature of the polymers with siloxan as side chains. ${ }^{29}$ The essential role of the siloxane chain is to give the mobility to a compound through lowering the viscosity. Cyanophenyl benzoate liquid crystals gave highere diffraction efficiency (No 17, 18) than cyanobiphenyl liquid crystals (No 10, 16), which was also consistent with above discussion. Fine grating with $78 \%$ diffraction efficiency was formed with $10 \mathrm{wt} \%$ 4-cyanophenyl 4-\{(5-heptamethyltrisiloxan-

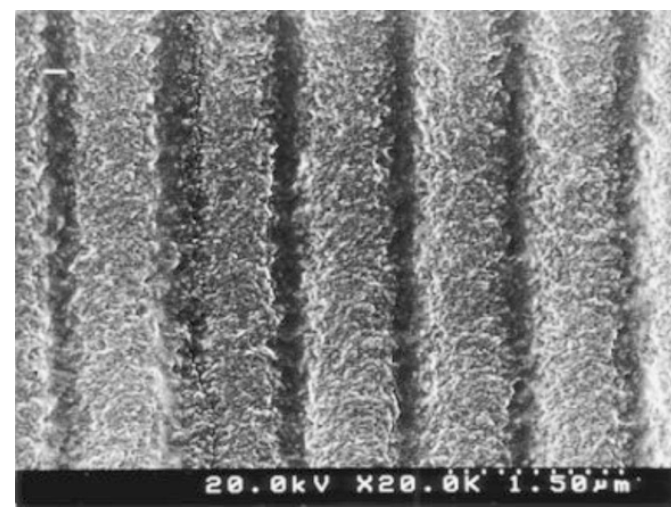

(a) 1-yl)pentyloxy fbenzoate (11OS3BE) using pentaerythrytol pentaacrylate-neopentylglycol diglycidyl ether-tripropylene glycol diacrylate $(4: 5: 1)$ as the polymer matrix component (No 18).

\section{Effect of Irradiation Power on the Diffraction Effi- ciency}

The influence of irradiation power on the diffraction was studied. The diffraction efficiency was saturated with the power higher than $15 \mathrm{~mW} / \mathrm{cm}^{2}$. Thus the optimum conditions for the formation of grating with the highest efficiency in the present system could be obtained with 5F-N2R-BGE [4:5:1] with $10 \mathrm{wt} \%$ 11OS3CB, $0.4 \mathrm{wt} \% \mathbf{K C}$, and $3 \mathrm{wt} \%$ DPI under 15 $\mathrm{mW} / \mathrm{cm}^{2}$ irradiation power of Nd-YAG laser (532 $\mathrm{nm})$. Both too high irradiation power $\left(35 \mathrm{~mW} / \mathrm{cm}^{2}\right)$, or too low irradiation power $\left(2.5 \mathrm{~mW} / \mathrm{cm}^{2}\right)$ resulted in the decrease of the diffraction efficiency.

Under these conditions, even $\mathbf{5 C B}$ could give grating $(\mathrm{DE}=34 \%)$, although the grating morphology was not as well-controlled as in the case of $110 S 3 \mathrm{CB}$, as shown in Figure 8.

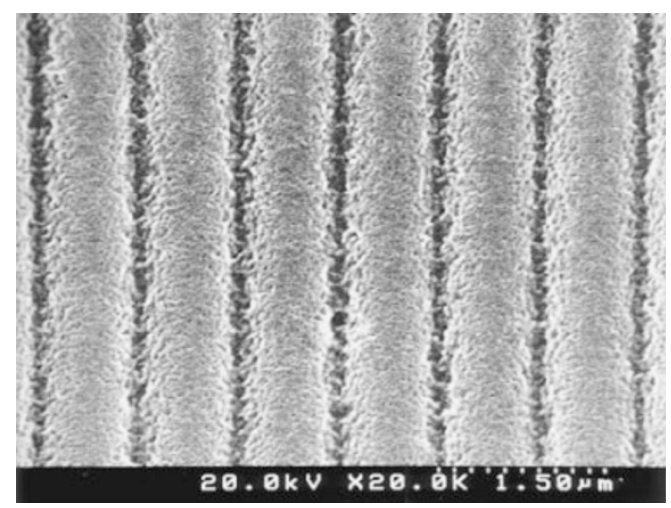

(b)

Figure 8. SEM morphology of grating made with different LC $(10 \mathrm{wt} \%)$, prepared with $\mathbf{5 F}: \mathbf{N 2 R}: \mathbf{B G E}=4: 5: 1$ (KC $0.4 \mathrm{wt} \%$, DPI 3 wt \%): (a) 11OS3CB, (b) 5CB. 
All these findings are consistent with the argument of the importance of the balance between polymerization and phase separation.

\section{Angular Selectivity of Grating Made with Various Incident Angle}

Angular selectivity of the gratings prepared with $110 S 3 C B$ was evaluated. It was found that the diffraction efficiency did not change so much at small incident angle such as $<30^{\circ}$. Reasonably narrow angular selectivity $\sim 5^{\circ}$ was obtained. ${ }^{27}$

\section{CONCLUSIONS}

Siloxane spacer of cyanobiphenyl liquid crystal dramatically increased the diffraction efficiency, due to the effective phase separation caused by the low viscosity, when combined with multi-functional acrylates, over a wide concentration range. Use of ringopening polymerizable bi-functional epoxides as one of the reactive cross-linking matrix component together with penta- or tetraacrylate initiated by $3,3^{\prime}$-carbonylbis(7-diethylaminocoumarin)-diphenyliodonium hexafluorophosphate greatly improved the diffraction efficiency of the formed grating. A fine grating with $70 \%$ and $78 \%$ diffractive efficiency and angular selectivity of about $5^{\circ}$ was formed with $10 \mathrm{wt} \%$ 4-cyano$4^{\prime}$ - $\{(5$-heptamethyltrisiloxan-1-yl)pentyloxy $\}$ biphenyl and 4-cyanophenyl 4-\{(5-heptamethyltrisiloxan-1-yl)pentyloxy\}benzoate using pentaerythrytol pentaacrylate-neopentylglycol diglycidyl ether-tripropylene glycol diacrylate (4:5:1) as the polymer matrix component.

Acknowledgment. This work was partly supported by a Grant-in-Aid for Scientific Research (16205016) from the Ministry of Education, Science, Sports, Culture and Technology, Japan.

\section{REFERENCES}

1. a) M. Kawabata, M. Harada, and Y. Takimoto, Photopolymerizable Composition, U.S. Patent No. 4,868,092 (1989). b) M. Kawabata, A. Sato, I. Sumiyoshi, T. Kubota, Proc. SPIE, 66, 1914 (1993).

2. R. L. Sutherland, L. V. Natarajan, V. P. Tondiglia, and T. J. Bunning, Chem. Mater., 5, 1533 (1993).

3. R. L. Sutherland, V. P. Tondiglia, L. V. Natarajan, T. J. Bunning, and W. W. Adams, Appl. Phys. Lett., 64, 1074 (1994).

4. R. L. Sutherland, L. V. Natarajan, V. P. Tondiglia, T. J. Bunning, and W. W. Adams, Proc. SPIE, 2152, 303 (1994).

5. V. P. Tondiglia, L. V. Natarajan, R. L. Sutherland, T. J. Bunning, and W. W. Adams, Opt. Lett., 20, 1325 (1995).
6. a) T. J. Bunning, L. V. Natarajan, V. P. Tondiglia, R. L. Sutherland, D. L. Vezie, and W. W. Adams, Polymer, 36, 299 (1995).

b) R. A. Vaia, D. W. Tomlin, and T. J. Bunning, Polymer, 42, 1055 (2001).

7. L. V. Natarajan, R. L. Sutherland, V. P. Tondiglia, V. P. T. J. Bunning, and W. W. Adams, J. Nonlinear Opt. Phys. Mater., 5, 89 (1996).

8. "Photoinitiation, Photopolymerization, and Photocuring: Fundamentals and Applications," J. P. Fouassier and JeanPierre, Ed., Hanser/Gardner, Cincinnati, OH, 1995.

9. "Lasers in Polymer Science and Technology: Applications," J. P. Fouassier and J. F. Rabek, Ed., CRC Press, Boca Raton, FL, 1990 .

10. W. K. Smothers, B. M. Monroe, A. W. Weber, and D. E. Keys, Proc. SPIE, 1212, 20 (1990).

11. N. Sasa and T. Yamaoka, Chem. Mater., 5, 1434 (1993).

12. B. M. Monroe, W. J. Smothers, D. E. Keys, R. R. Krebs, D. J. Mickish, A. F. Harrington, S. C. Schickers, M. K. Armstrong, D. M. T. Chan, and C. I. Weathers, J. Imaging Sci., 35, 19 (1991).

13. B. M. Monroe, J. Imaging Sci., 35, 25 (1991).

14. K. Tanaka, K. Kato, S. Tsuru, and S. Sakai, J. SID, 2, 37 (1994).

15. K. Tanaka, K. Kato, S. Tsuru, and S. Sakai, SID 95 Digest, 26, 267 (1995).

16. R. L. Sutherland, L. V. Natarajan, V. P. Tondiglia, and T. J. Bunning, Proc. SPIE, 3421, 8 (1998).

17. B. Parker, "Switchable Optical Elements Merge Optics and Electronics," Laser Focus World, March 1999, p. 135.

18. L. H. Domash, Y. M. Chen, B. N. Gomatam, C. M. Gozewski, R. L. Sutherland, L. V. Natarajan, V. P. Tondiglia, T. J. Bunning, T. J., and W. W. Adams, Proc. SPIE, 2689, 188 (1996).

19. R. L. Sutherland and L. V. Natarajan, Liq. Cryst. Today, 7, 1 (1997).

20. T. J. Bunning, L. V. Natarajan, V. P. Tondiglia, and R. L. Sutherland, Аnnu. Rev. Mater. Sci., 30, 83 (2000).

21. R. T. Pouge, L. V. Nartarajan, S. A. Siwecki, V. P. Tondiglia, R. L. Sutherland, and T. J. Bunning, Polymer, 41, 733 (2000).

22. L. V. Natarajan, C. K. Shepherd, D. M. Brandelik, R. L. Sutherland, S. Chandra, V. P. Tondiglia, D. Tomlin, and T. J. Bunning, Chem. Mater., 15, 2477 (2003).

23. M. D. Sakar, J. Qi, and G. P. Crawford, Polymer, 43, 7335 (2002).

24. Y. H. Cho, M. He, B. K. Kim, and Y. Kawakami, Sci. Technol. Adv. Mater., 5, 319 (2004).

25. Y. H. Cho, R. Kawade, T. Kubota, and Y. Kawakami, Sci. Technol. Adv. Mater., 6, 435 (2005).

26. C. S. Hsu, J. H. Lin, L. R. Chou, and G. H. Hsiue, Macromolecules, 25, 7126 (1992).

27. H. Kogelnik, Bell Syst. Tech. J., 48, 2909 (1969).

28. Y. H. Cho, C. W. Shin, N. Kim, B. K. Kim, and Y. Kawakami, Chem. Mater., 17, 6263 (2005).

29. Y. Kawakami, T. Aoki, H. Hisada, Y. Yamamura, and Y. Yamashita, Polym. Commun., 26, 133 (1985). 